\title{
Ф.В. Грушин
}

\section{НОВЫЙ УГОЛОВНО-ИСПОЛНИТЕЛЬНЫЙ КОДЕКС РОССИЙСКОЙ ФЕДЕРАЦИИ: ПРЕДМЕТ ПРАВОВОГО РЕГУЛИРОВАНИЯ И СТРУКТУРА}

\begin{abstract}
Рассматривается возможность принятия нового Уголовно-исполнительного кодекса Российской Федерации с позиций расширения предмета правового регулирования уголовно-исполнительного права и уголовноисполнительного законодательства за счет мер уголовно-правового характера и мер пресечения.
\end{abstract}

Ключевые слова: уголовно-исполнительный кодекс, уголовно-исполнительное право, уголовно-исполнительное законодательство.

В последнее время все чаще возникает дискуссия о необходимости принятия нового Уголовно-исполнительного кодекса Российской Федерации. Одним из первых идею принятия нового УИК РФ высказал в 2010 г. В.Н. Орлов [1, с. 368-373]. В 2016 г. группой ученых была разработана Общая часть нового Уголовноисполнительного кодекса Российской Федерации [2].

Сложившаяся ситуация с законодательным регулированием уголовно-исполнительных правоотношений крайне отрицательно оценивается как практиками, так и учеными. Несколько лет назад был проведен экспертный опрос, в котором участвовали ведущие специалисты в сфере уголовно-исполнительного права из России, Белоруссии и Казахстана [3, с. 5-6]. В результате опроса были получены следующие результаты. Все эксперты считают, что в той или иной степени требуется совершенствование УИК РФ: необходимо принятие нового УИК РФ - полагают 38,2\%; требуется новая редакция УИК РФ - 32,4\%; следует ограничиться внесением изменений в отдельные нормы УИК РФ - 29,4\%.

Если оценивать перспективы принятия нового УИК РФ, то следует согласиться с В.И. Селиверстовым, который абсолютно верно утверждает, что низкое качество действующего кодекса не может служить основанием для принятия нового, так как в этом случае достаточно внесения необходимых изменений и правок [4, с. 64].

Полагаем возможным утверждать, что принятие нового УИК РФ должно в первую очередь обосновываться расширением предмета уголовно-исполнительного права и законодательства, а также соответствующим изменением структуры кодекса.

Некоторыми учеными высказывалась идея расширения предмета уголовно-исполнительного права и законодательства за счет правового регулирования исполнения административных наказаний (в частности, административного штрафа, административного ареста, обязательных работ), предусмотренных Кодексом об административных правонарушениях [5, с. 66-68]. Как ни удивительно это звучит, но данную идею еще в середине прошлого века озвучивал профессор Н.А. Стручков. По его мнению, к исправительно-трудовому законодательству возможно было отнести нормы, устанавливающие порядок и условия исполнения отдельных мер административного воздействия [6, с. 62-67]. Полагаем, что рассматриваемое предложение в условиях современного развития общественных отношений слишком карди- нально, так как в данном случае речь уже будет идти не об уголовно-исполнительном праве, а, скорее, о новой мегаотрасли - «исполнительном праве» [7, с. 40].

Кроме того, отдельные ученые высказываются за идею включения в сферу уголовно-исполнительного регулирования исполнение мер постпенитенциарного воздействия. Например, В.Н. Чорный к уголовноисполнительному праву относит ресоциализационные правоотношения как пенитенциарного, так и постпенитенциарного периода [8, с. 28]. А.Я. Гришко также указывает, что «одной из первопричин разбалансированности уголовно-исполнительного законодательства является непризнание постпенитенциарной адаптации предметом уголовно-исполнительного права» [9, с. 89].

В то же время в рамках классического представления об уголовно-исполнительном праве отношения, возникающие после освобождения от отбывания наказания, к рассматриваемой отрасли права не относятся [10, с. 32-39]. При анализе данного вопроса полагаем необходимым согласиться с В.А. Уткиным, который утверждает, что необходимо «регулировать отношения в сфере постпенитенциарной ресоциализации (социальной адаптации) освобожденных не уголовно-исполнительным, а «социальным» законодательством, или законодательством о социальной помощи» [11, с. 79].

Таким образом, расширение предмета возможно и необходимо по двум основным направлениям: во-первых, за счет правового регулирования в уголовно-исполнительном законодательстве исполнения мер уголовноправового характера, предусмотренных Уголовным кодексом РФ, а во-вторых, за счет правового регулирования исполнения мер пресечения, предусмотренных Уголовно-процессуальным кодексом РФ.

Прежде чем оценивать исполнение мер уголовноправового характера с точки зрения расширения предмета уголовно-исполнительного права и законодательства, необходимо отметить, что в науке уголовного и уголовно-исполнительного права существует достаточно большое количество точек зрения на сущность рассматриваемого института [12, с. 528]. Например, B.А. Уткин весьма обосновано предпочитает говорить не о мерах уголовно-правового характера, как это предусмотрено ч. 2 ст. 2 УИК РФ, а о мерах уголовноправового принуждения [7, с. 39-40]. Следует отметить, что в УК РФ (и это говорит о его несовершенстве) наряду с понятием «меры уголовно-правового характе- 
ра» используются такие категории, как «иные меры уголовно-правового характера», «меры уголовной ответственности», «меры уголовно-правового воздействия» $[13$, с. $56-57]$.

Действующий УИК РФ определяет правовое регулирование исполнения следующих мер уголовноправового характера, предусмотренных Уголовным кодексом РФ:

- отсрочка от отбывания наказания беременной женщине, женщине, имеющей ребенка в возрасте до четырнадцати лет, мужчине, имеющему ребенка в возрасте до четырнадцати лет и являющемуся единственным родителем (ст. 82 УК РФ). Порядок исполнения данной меры определен ст.ст. 177, 178 УИК РФ;

- отсрочка отбывания наказания больным наркоманией (ст. 82.1 УК РФ). Порядок исполнения данной меры определен ст. 178.1 УИК РФ;

- условное осуждение (ст.ст. 73, 74 УК РФ). Порядок осуществления контроля за условно осужденными определен ст.ст. 187-190 УИК РФ.

Частично в УИК РФ (ст. 18) представлены нормы, определяющие некоторые особенности исполнения принудительных мер медицинского характера, предусмотренных гл. 15 УК РФ. Однако, учитывая содержание ст. 18 УИК РФ, а также то, что данная статья находится в общей части УИК РФ, говорить о полноценном правовом регулировании исполнения этой меры не приходится.

В отношении других мер уголовно-правового характера, предусмотренных УК РФ, уголовно-исполнительное законодательство вообще не содержит никаких норм. Это касается таких мер уголовно-правового характера, как конфискация имущества (ст.ст. 104.1-104.3 УК РФ), судебный штраф (ст.ст. 104.4, 104.5 УК РФ), принудительные меры воспитательного воздействия в отношении несовершеннолетних, совершивших преступления небольшой или средней тяжести (ст.ст. 90, 91, ч. 1 ст. 92 УК РФ), в том числе специальная мера воспитательного воздействия в виде помещения в специальное учебно-воспитательное учреждение закрытого типа в отношении несовершеннолетних, осужденных к лишению свободы за совершение преступления средней тяжести, а также тяжкого преступления (ч. 2-5 ст. 92 УК РФ). В УИК РФ не содержится норм о порядке осуществления контроля за условно-досрочно освобожденными, предусмотренного ст.ст. 79, 93 УК РФ. При этом часть норм, связанных с исполнением данной меры, содержится в самом УК РФ (ч. 6, 7 ст. 79 УК РФ).

В результате складывается ситуация, когда нормы об исполнении мер уголовно-правового характера содержатся в различных законах - частично в Уголовноисполнительном кодексе, частично в Уголовном кодексе, а также в иных нормативно-правовых актах. Например, порядок осуществления конфискации определен как в УК РФ, так и в нормах Федерального закона от 2 октября 2007 г. № 229-Ф3 «Об исполнительном производстве» ${ }^{1}$. Полагаем, что нормы, регулирующие однородные общественные отношения, в данном случае нормы, определяющие порядок и условия исполнения

\footnotetext{
${ }^{1}$ См.: Собрание законодательства РФ. 2007. № 41. Ст. 4849.
}

мер уголовно-правого характера, должны содержатся в новом Уголовно-исполнительном кодексе, что приведет к упорядочиванию правового регулирования и более эффективному правоприменению учреждениями и органами, на которые возложено исполнение рассматриваемых мер.

Если в отношении мер уголовно-правового характера большинство ученых приходят к выводу о необходимости правового регулирования их исполнения в УИК РФ, то в отношении возможности расширения предмета уголовно-исполнительного права и законодательства за счет правового регулирования исполнения мер пресечения, предусмотренных УПК РФ, позиции ученых расходятся.

Например, Ю.А. Головастова однозначно высказывается против включения в предмет уголовно-исполнительного права исполнения мер пресечения, так как, по ее мнению, они относятся к уголовно-процессуальным правоотношениям и противоречат природе уголовноисполнительного права [10, с. 31-32].

В.И. Селиверстов, говоря о необходимости принятия нового УИК РФ, не высказывал мысль о расширении предмета уголовно-исполнительного права за счет правового регулирования исполнения мер пресечения [2, c. 11-23].

В.А. Уткин остается на позициях классического уголовно-исполнительного права и не относит рассматриваемые меры к предмету уголовно-исполнительного права, при этом ученый не исключает возможности расширения предмета уголовно-исполнительного права в данном контексте за счет правового регулирования исполнения мер пресечения при широком толковании предмета уголовно-исполнительного права [7, с. 40].

В то же время В.Н. Орлов однозначно выступает за то, что «уголовно-исполнительное законодательство должно регламентировать процедуру исполнения, отбывания уголовно-процессуальных мер пресечения» [14, c. 122]. Соглашается с данным посылом и А.П. Скиба $[15$, с. 10$]$.

Одним из ключевых моментов этой дискуссии является анализ правоотношений, регулирующих институт содержания под стражей подозреваемых и обвиняемых в совершении преступлений.

Существует как минимум три точки зрения о месте данных правоотношений в отечественной правовой системе. Представители уголовно-процессуального права утверждают о приоритете уголовно-процессуальных правоотношений, хотя и допускают, что существуют особенности, связанные с режимом содержания подозреваемых и обвиняемых в следственных изоляторах, а также со спецификой данных правоотношений [16, с. 191192; 17, с. 472]. Представители второй точки зрения высказываются за существование самостоятельной правовой отрасли. Так, по мнению В.Н. Андреева, правоотношения в процессе содержания подозреваемых и обвиняемых под стражей должны регулироваться особой отраслью права - «стражным правом» [18, с. 169]. Высказанную идею поддержал и А.М. Потапов [19, с. 37].

Учитывая специфику института содержания под стражей, признаваемую даже специалистами в сфере уголовно-процессуального права, полагаем, что правовое 
регулирование данных правоотношений необходимо включить в предмет уголовно-исполнительного права и законодательства. В поддержку данного решения можно привести следующие практические обстоятельства:

- порядок и условия содержания под стражей весьма схожи с порядком и условиями исполнения лишения свободы, например в тюрьмах;

- следственные изоляторы структурно входят в уголовно-исполнительную систему;

- помимо подозреваемых и обвиняемых в следственных изоляторах содержатся и осужденные (например, оставленные для выполнения работ по хозяйственному обслуживанию), которые являются субъектами уголовно-исполнительных правоотношений;

- в настоящее время при многих исправительных учреждениях созданы так называемые ПФРСИ (помещения, функционирующие в режиме следственного изолятора);

- правоотношения, возникающие при исполнении меры пресечения в виде заключения под стражу, изучаются во всех вузах страны в рамках учебной дисциплины «Уголовно-исполнительное право».

Кроме того, с теоретической точки зрения возможно провести аналогию с уголовным правом и законодательством, где определяются виды уголовных наказаний, а порядок их исполнения и отбывания содержится в уголовно-исполнительном законодательстве. Полагаем, что по этому же принципу должно быть построено исполнение и отбывание мер пресечения.

Помимо содержания под стражей, УПК РФ предусматривает и иные меры пресечения, требующие самостоятельной правовой регламентации по порядку их исполнения и отбывания. При этом необходимо отметить, что такие меры пресечения, как домашний арест, запрет определенных действий и частично залог исполняются уголовно-исполнительными инспекциями, являющимися учреждениями уголовно-исполнительной системы.

Анализируя УПК РФ, следует указать, что в УИК РФ также ничего не говорится о контроле за отдельными категориями осужденных, которым в соответствии со ст. 398 УПК РФ может быть предоставлена отсрочка исполнения приговора:

- в связи с болезнью осужденного, препятствующей отбыванию наказания;

- в связи с тяжкими последствиями или угрозой их возникновения для осужденного или его близких родственников, вызванными пожаром или иным стихийным бедствием, тяжелой болезнью или смертью единственного трудоспособного члена семьи, другими исключительными обстоятельствами.
При этом контроль за другими категориями осужденных, указанными в ст. 398 УПК РФ (беременные женщины, осужденные, имеющие малолетнего ребенка и являющиеся единственным родителем, осужденные признанные больными наркоманией), действующим уголовно-исполнительным законодательством предусмотрен.

Полагаем, что уголовно-исполнительное законодательство должно содержать нормы, регулирующие порядок исполнения отсрочки исполнения приговора в отношении всех категорий осужденных, указанных в ст. 398 УПК РФ.

Также считаем, что нормы, изложенные в ст. 398 УПК РФ, дублируют в большей части нормы ст.ст. 81, 82, 82.1 УК РФ, а отсрочка в связи с тяжкими последствиями или угрозой их возникновения для осужденного или его близких родственников вообще не предусмотрена УК РФ, что свидетельствует о рассогласованности данных нормативно-правовых актов.

Подводя итоги изложенному, а также принимая во внимание мнение авторского коллектива по подготовке общей части нового УИК РФ [2, с. 14-29], полагаем, что назрела необходимость принятия нового Уголовноисполнительного кодекса с учетом сложившейся в настоящее системы общественных отношений.

Весьма интересную идею двухуровневого Уголовно-исполнительного кодекса РФ предложил В.И. Селиверстов: том первый - исполнение и отбывание уголовных наказаний (части общая и особенная); том второй - исполнение и отбывание мер уголовно-правового характера (части общая и особенная) [4, с. 68].

Полагаем, что предложенную В.И. Селиверстовым идею двухуровневого Уголовно-исполнительного кодекса РФ возможно развить до трехуровневого, т.е. добавить том третий - исполнение и отбывание уголовно-процессуальных мер пресечения (части общая и особенная).

Естественно, что не представляется возможным принятие нового УИК РФ без одновременной разработки изменений Уголовного кодекса РФ. Не вдаваясь в бурную дискуссию ученых в сфере уголовного права о необходимости принятия нового УК РФ или новой редакции УК РФ, мы полагаем, что принятие нового УИК РФ не потребует одновременного принятия именного нового УК РФ, так как в нем потребуются изменения в основном в части системы уголовных наказаний и мер уголовно-правового характера. На наш взгляд, следует согласиться с мнением А.В. Наумова, полагающего, что принятие нового Уголовного кодекса возможно только в случае кардинальной смены уголовной политики, вызванной также кардинальными изменениями государственного и общественно-политического плана [20, с. 14].

\section{ЛИТЕРАТУРА}

1. Орлов В.Н. Нужен новый Уголовно-исполнительный кодекс РФ: криминопенологический взгляд // Российский криминологический взгляд. 2010. № 2. С. 368-373.

2. Общая часть нового Уголовно-исполнительного кодекса Российской Федерации: итоги и обоснования теоретического моделирования / под ред. В.И. Селиверстова. М. : Юриспруденция, 2017. 328 с.

3. Грушин Ф.В. Влияние системы факторов на развитие уголовно-исполнительной политики и уголовно-исполнительного законодательства Российской Федерации / под науч. ред. В.И. Селиверстова. М. : ИНФРА-М, 2017. 208 с.

4. Селиверстов В.И. Проблемы качества уголовно-исполнительного законодательства в Российской Федерации и его кодификации // Международный пенитенциарный форум «Преступление, наказание, исправление» (к 20-летию принятия Конституции Российской Федерации) : сб. тез. выступлений участников (Рязань, 5-6 декабря 2013 г.). Рязань : Академия ФСИН России, 2013. С. 62-69. 
5. Орлов В.Н. Концепции профессора Н.А. Стручкова и перспективы развития уголовно-исполнительного права // Вестник Университета имени О.Е. Кутафина (МГЮА). 2017. № 7. С. 62-68.

6. Стручков Н.А. Содержание советского исправительно-трудового законодательства и значение для его разработки кодификации уголовного законодательства // Материалы теоретической конференции по вопросам советского исправительнотрудового права (май 1957). М., 1957. С. 62-67.

7. Уткин В.А. Уголовно-исполнительная деятельность и предмет уголовно-исполнительного права // Уголовно-исполнительное право. 2016. № 2 (24). С. 39-43.

8. Чорный В.Н. Тенденции развития уголовно-исполнительного права в современных условиях // От исправительно-трудового права к уголовно-исполнительной отрасли : материалы междунар. науч.-практ. семинара. Рязань : Академия права и управления ФСИН России, 2006. С. 25-29.

9. Гришко А.Я. Уголовно-исполнительный закон будущего: направления реформирования // Юридическая наука и правоохранительная практика. 2014. № 4 (30). С. 88-93.

10. Головастова Ю.А. Уголовно-исполнительное право как отрасль российского права: предмет, метод, источники, система / под науч. ред. В.И. Селиверстова. М. : Юриспруденция, 2019. 560 с.

11. Уткин B.A. Ресоциализация освобожденных от наказания: история и современность // Уголовная юстиция. 2014. № 1 (3). C. $75-80$.

12. Отрасли законодательства и отрасли права Российской Федерации: общетеоретический, межотраслевой, отраслевой и историко-правовой аспекты / под общ. ред. Р.Л. Хачатурова. М. : Юрлитинформ, 2017. 584 с.

13. Головастова Ю.А. Модификация предмета уголовно-исполнительного права как отрасли права // Уголовно-исполнительное право. 2016. № 2 (24). С. 56-59.

14. Орлов В.Н. Необходимо принять новый Уголовно-исполнительный кодекс Российской Федерации // Рецидивная преступность и пути ее преодоления : материалы выездного заседания Региональной общественной организации «Союз криминалистов и криминологов» (Рязань, 15 апреля 2011 г.). Рязань : Академия ФСИН России, 2011. С. 120-132.

15. Скиба А.П. Некоторые проблемы разграничения уголовно-процессуального и уголовно-исполнительного регулирования // Уголовно-исполнительное право. 2015. № 2 (20). С. 9-13.

16. Гельдибаев М.X. Обеспечение прав и свобод человека и гражданина в сфере уголовно-процессуального принуждения : дис. ... д-ра юрид. наук. СПб., 2001. 332 с.

17. Баландюк O.В. Правовая природа и отраслевая принадлежность деятельности по исполнению меры пресечения в виде заключения под стражу (постановка проблемы) // Вестник Нижегородской академии МВД России. 2016. № 2 (34). С. 470-472.

18. Андреев B.Н. Правовое положение подозреваемых и обвиняемых, содержащихся под стражей. М. : Права человека, 2000. $204 \mathrm{c}$.

19. Потапов А.М. Об особенностях развития уголовно-исполнительных правоотношений на современном этапе // Вестник института : науч.-практ. журнал Вологодского института права и экономики ФСИН России. Преступление. Наказание. Исправление. 2008. № 3. С. 36-37.

20. Наумов A.B. Проблемы кодификации российского уголовного законодательства: новый Уголовный кодекс или новая редакция кодекса? // Общество и право. 2010. № 5 (32). С. 13-17.

\section{New Penal Code of the Russian Federation: Subject of Legal Regulation and Structure}

Ugolovnaya yustitsiya - Russian Journal of Criminal Law, 2019, no. 14, pp. 82-86. DOI 10.17223/23088451/14/17

Fedor V. Grushin, Academy of the Federal Penitentiary Service of Russia (Ryazan, Russian). E-mail: fedor062@yandex.ru

Keywords: penal code, penal law, penal legislation.

Practitioners as well as scholars extremely negatively assess the current legislative regulation of penal relations. The recent years have seen an increased discussion of the need for a new Penal Code of the Russian Federation, which should primarily be justified by the expansion of the subject of penal law and legislation as well as changes in the Code structure. The expansion of the subject is possible and necessary in two main areas: firstly, in the legal regulation of penal measures provided for by the Criminal Code of the Russian Federation and, secondly, in the legal regulation of preventive measures provided for by the Criminal Procedure Code of the Russian Federation. The current Penal Code of the Russian Federation determines the legal regulation of only certain penal measures provided for by the Criminal Code of the Russian Federation. However, it does not specify norms on the procedure for monitoring such penal measures as: confiscation of property (Articles 104.1 - 104.3 of the Criminal Code of the Russian Federation); judicial fine (Articles 104.4, 104.5 of the Criminal Code of the Russian Federation); compulsory educational measures for minors who have committed crimes of minor or medium gravity (Articles 90, 91, part 1 of Article 92 of the Criminal Code of the Russian Federation). There is a situation when the rules on the implementation of penal measures can be found in various laws - partly in the Penal Code, partly in the Criminal Code as well as in other regulatory legal acts. While many scholars agree on the necessary legal regulation of penal measures in the Penal Code of the Russian Federation, they still disagree on the possible expansion of the subject of penal law and legislation through legal regulation of preventive measures provided for by the Code of Criminal Procedure of the Russian Federation. One of the key points in their discussion is the analysis of legal relations governing the institution of detention of suspects and accused of crimes. The author argues that thre is an urgent need for a new Penal Code, taking into account the current system of public relations. The two-level Penal Code of the Russian Federation proposed by V.I. Seliverstov can be developed into a three-level system through adding Volume 3 about the execution and serving of penal measures of restraint (general and special parts).

\section{References}

1. Orlov, V.N. (2010) Nuzhen novyy Ugolovno-ispolnitel'nyy kodeks RF: kriminopenologicheskiy vzglyad [Need for a new Penal Code of the Russian Federation: A criminopenological view]. Rossiyskiy kriminologicheskiy vzglyad-Russian Criminological Outlook. 2. pp. 368-373. 
2. Seliverstov, V.I. (ed.) (2017) Obshchaya chast' novogo Ugolovno-ispolnitel'nogo kodeksa Rossiyskoy Federatsii: itogi i obosnovaniya teoreticheskogo modelirovaniya [The general part of the new Penal Code of the Russian Federation: results and justifications of theoretical modeling]. Moscow: Yurisprudentsiya.

3. Grushin, F.V. (2017) Vliyanie sistemy faktorov na razvitie ugolovno-ispolnitel'noy politiki $i$ ugolovno-ispolnitel'nogo zakonodatel'stva Rossiyskoy Federatsii [The influence of the system of factors on the development of penal policy and penal law of the Russian Federation]. Moscow: INFRA-M.

4. Seliverstov, V.I. (2013) [The problems of the quality of penal legislation in the Russian Federation and its codification]. Prestuplenie, nakazanie, ispravlenie ( $k$ 20-letiyu prinyatiya Konstitutsii Rossiyskoy Federatsii) [Crime, Punishment, Correction (on the 20th anniversary of the adoption of the Constitution of the Russian Federation)]. Proc. of the International Forum. Ryazan, December 5-6, 2013. Ryazan: Academy of the Federal Penitentiary Service of Russia. pp. 62-69. (In Russian).

5. Orlov, V.N. (2017) Ideas of Professor Nikolay A. Struchkov and prospects for the development of penal law. Vestnik Universiteta imeni O.E. Kutafina (MGYuA) - Courier of the Kutafin Moscow State Law University (MSAL). 7. pp. 62-68. (In Russian). DOI: 10.17803/2311-5998.2017.35.7.062-068

6. Struchkov, N.A. (1957) Soderzhanie sovetskogo ispravitel'no-trudovogo zakonodatel'stva i znachenie dlya ego razrabotki kodifikatsii ugolovnogo zakonodatel'stva [The content of Soviet Corrective Labour Law and the importance of criminal law codification for its development]. In: Studenikin, S.S. (ed.) Materialy teoreticheskoy konferentsii po voprosam sovetskogo ispravitel'no-trudovogo prava (may 1957) [Materials of a theoretical conference on Soviet Labour Law (May 1957)]. Moscow: [s.n.]. pp. 62-67.

7. Utkin, V.A. (2016) Ugolovno-ispolnitel'naya deyatel'nost' i predmet ugolovno-ispolnitel'nogo prava [Penal activity and the subject of penal law]. Ugolovno-ispolnitel'noe pravo. 2(24). pp. 39-43.

8. Chornyy, V.N. (2006) [Trends in the development of penal law in modern conditions]. Ot ispravitel'no-trudovogo prava $k$ ugolovnoispolnitel'noy otrasli [From corrective labour law to the penal branch]. Proc. if the International Seminar. Ryazan: Academy of Law and Management of the Federal Penitentiary Service of Russia. pp. 25-29. (In Russian).

9. Grishko, A.Ya. (2014) Penal law of the future: directions of reforming. Yuridicheskaya nauka i pravookhranitel'naya praktika Legal Science and Law Enforcement Practice. 4(30). pp. 88-93. (In Russian).

10. Golovastova, Yu.A. (2019) Ugolovno-ispolnitel'noe pravo kak otrasl' rossiyskogo prava: predmet, metod, istochniki, sistema [Penal law as a branch of Russian law: subject, method, sources, system]. Moscow: Yurisprudentsiya.

11. Utkin, V.A. (2014) Resocialization of persons released from punishment: past and present. Ugolovnaya yustitsiya - Russian Journal of Criminal Law. 1(3). pp. 75-80. (In Russian).

12. Khachaturov, R.L. (ed.) (2017) Otrasli zakonodatel'stva i otrasli prava Rossiyskoy Federatsii: obshcheteoreticheskiy, mezhotraslevoy, otraslevoy $i$ istoriko-pravovoy aspekty [Branches of legislation and law of the Russian Federation: General theoretical, interbranch, industry and historical aspects]. Moscow: Yurlitinform.

13. Golovastova, Yu.A. (2016) Modifikatsiya predmeta ugolovno-ispolnitel'nogo prava kak otrasli prava [Modification of the subject of penal law as a branch of law]. Ugolovno-ispolnitel'noe pravo. 2(24). pp. 56-59.

14. Orlov, V.N. (2011) [It is necessary to adopt the new Criminal Executive Code of the Russian Federation]. Retsidivnaya prestupnost' i puti ee preodoleniya [Recidivism and ways to overcome it]. Proc. of the Meeting of the Regional Public Organization "The Union of Criminologists and Criminologists". Ryazan, April 15, 2011. Ryazan: Academy of the Federal Penitentiary Service of Russia. pp. 120-132. (In Russian).

15. Skiba, A.P. (2015) Nekotorye problemy razgranicheniya ugolovno-protsessual'nogo i ugolovno-ispolnitel'nogo regulirovaniya [Some problems of distinguishing between criminal procedure and penal regulation]. Ugolovno-ispolnitel'noe pravo. 2(20). pp. 9-13.

16. Geldibaev, M.Kh. (2001) Obespechenie prav i svobod cheloveka i grazhdanina v sfere ugolovno-protsessual'nogo prinuzhdeniya [Ensuring the rights and freedoms of person and citizen in the field of criminal procedure coercion]. Law Dr. Diss. St. Petersburg.

17. Balandyuk, O.V. (2016) Pravovaya priroda i otraslevaya prinadlezhnost' deyatel'nosti po ispolneniyu mery presecheniya v vide zaklyucheniya pod strazhu (postanovka problemy) [Legal nature and industry affiliation of activities to implement a preventive measure in the form of detention (statement of the problem)]. Vestnik Nizhegorodskoy akademii MVD Rossii. 2(34). pp. 470-472.

18. Andreev, V.N. (2000) Pravovoe polozhenie podozrevaemykh i obvinyaemykh, soderzhashchikhsya pod strazhey [Legal status of suspects and accused in custody]. Moscow: Prava cheloveka.

19. Potapov, A.M. (2008) Ob osobennostyakh razvitiya ugolovno-ispolnitel'nykh pravootnosheniy na sovremennom etape [On the specificity of the development of penal relations at the present stage]. Vestnik instituta. Prestuplenie. Nakazanie. Ispravlenie - Institute Bulletin: Crime, Punishment, Correction. 3. pp. 36-37.

20. Naumov, A.V. (2010) Problemy kodifikatsii rossiyskogo ugolovnogo zakonodatel'stva: novyy Ugolovnyy kodeks ili novaya redaktsiya kodeksa? [Problems of codification of Russian criminal legislation: a new Criminal Code or a new version of the Code?]. Obshchestvo i pravo - Society and Law. 5(32). pp. 13-17. 